\title{
Posturas ideológicas contrastan con las respuestas científicas a las necesidades de salud mental de las poblaciones del Brasil y de las Américas
}

He leído con sumo interés la nota que el profesor Valentim Gentil ha enviado a la Revista Brasileira de Psiquiatria. Es muy importante que un distinguido docente universitario tome partido en temas vinculados a la atención de los hospitales psiquiátricos; es muy frecuente que las universidades se desentiendan del problema. Su actitud merece ser destacada. Infelizmente, el contenido de su nota está cargada de ideología. Ideologías no son susceptibles de confirmación o de ser refutadas, excepto con otras interpretaciones ideológicas. El profesor Gentil tiene derecho a opinar según la ideología que lo orienta. El problema surge cuando ofrece información equivocada y cuando lo hace sin investigar los datos de manera apropiada. Esto resulta sumamente extraño en un investigador universitario que debe guiar sus afirmaciones sobre los hechos de manera objetiva y desapasionada, a fin de no confundirse a si mismo y confundir al lector. Es particularmente extraño que los errores se refieran precisamente al papel de la Organización Panamericana de la Salud siendo que es un miembro destacado de un Centro Colaborador de OPS-OMS. Desde 1990 hasta 1997, cuando renuncié a mi cargo, jamás me solicitó aclaración alguna que hubiera merecido respuesta inmediata dado su condición de miembro de la comunidad de OMS y de OPS.

Veamos:

1. La Conferencia de Caracas (noviembre de 1990) convocada por la Organización Panamericana de la Salud/Organización Mundial de la Salud, y que se realizó bajo el auspicio de la Organización Mundial de la Salud, la Asociación Mundial de Psiquiatría, la Asociación Psiquiátrica de América Latina, la Federación Mundial de Salud Mental, la Asociación Mundial de Rehabilitación Psicosocial, la Comisión Interamericana de Derechos Humanos de la OEA y la Sociedad Venezolana de Psiquiatría contó también con el apoyo de instituciones europeas, entre ellas el Instituto Mario Negri, en la sazón Centro Colaborador de la OMS. La financiación estuvo a cargo de OPS gracias a una partida especial de US\$ 40.000,00 otorgada por el Dr. Carlyle Guerra de Macedo, en aquel momento director de OPS.

2. Una lectura del libro que recogió las presentaciones y recomendaciones de la Conferencia de Caracas permite identificar las bases mundiales y latinoamericanas de larga data de la Declaración que lleva el nombre de la ciudad (en relación a las últimas, desde que en la década del cincuenta el Dr. CA Seguin en Lima, Peru, y el Dr. M Goldenberg en Lanus, Buenos Aires, Argentina crearan servicios comunitarios, hasta más recientemente cuando el Dr. R. Tykanori desarrolló servicios en San- tos, S. Paulo). La citada Declaración fue aceptada por aclamación en el día 14 de noviembre de 1990 (cabe notar que existe una versión en portugués del libro publicado por el Ministerio de la Salud del Brasil, que merece ser consultada por los que se identifican con la misma y por los que la rechazan).

3. La Declaración no es un documento oficial de OPS, sin embargo conviene que el profesor Gentil reconozca que esa Declaración sirvió de base para uno de los incisos de la Resolución CD40.R19 de setiembre de 1997, resolución adoptada por unanimidad por todos los países de las Américas en la reunión anual que los ministros de salud mantienen en la sede de OPS. (Cabe notar también que esta Declaración se encuentra en varias publicaciones tanto de OMS, hecha en el periodo en el cual el Dr. Jorge Alberto Costa e Silva fue director del departamento de salud mental, como de OPS. Próximamente OPS publicará un libro vinculado a los derechos humanos que incluye la mencionada Declaración. En pocas palabras, de manera alguna esa es una Declaración que fuera condenada al anonimato). Aclaradas las afirmaciones equivocadas y parciales véanse, en síntesis, las bases para la acción y los propósitos de OPS con sus políticas en materia de asistencia psiquiátrica:

Bases para la acción:

1. Las necesidades de la salud mental en nuestras poblaciones son de gran magnitud;

2. La mayor parte de las necesidades poblaciones no está satisfecha;

3. El sistema de atención con base en la cama del hospital psiquiátrico, sea moderno o antiguo, no es adecuado para disminuir la brecha entre las necesidades de las poblaciones y la oferta de servicios;

4. El hospital psiquiátrico, por lo general, ha sido responsable en no pequena medida por el estigma que rodea las enfermedades mentales como resultado de las violaciones de los derechos humanos que se producen en su seno, sean por comisión o por omisión.

Propósitos:

1. Ampliar la red de asistencia, extendiéndola a la comunidad.

2. Fomentar la equidad, de manera que quien más necesite de atención la reciba oportunamente y en la medida de sus necesidades;.

3. Erradicar todo tipo de atención que genere estigma y que provoque efectos adversos, no obstante la indiscutible positiva intención que pueda animar a los profesionales a apoyar la restitución de la salud; 
4. Estimular el uso de técnicas de atención que se hayan mostrado costo-efectivas, en sintonía con la cultura y sensibles a la materia de género;

Tanto el profesor Gentil como todo otro lector interesado pueden encontrar más informaciones sobre las bases y las políticas en publicaciones de OPS, en libros y en artículos de revistas científicas en castellano y en inglés.

Para concluir, es de celebrar que las universidades desempeñen un papel mayor en el mejoramiento de la atención, aportando sus enormes posibilidades por la formación de recursos humanos y, especialmente, por la investigación que alimente con datos objetivos políticas y programas. Consideraciones subjetivas, partidistas y diatribas personales, tal como desafortunadamente enlodan la nota del profesor Gentil, apenas pueden servir al propósito que nos anima a todos, inclusive el personal universitario, de ofrecer una asistencia en salud mental de alta calidad científica y técnica, equitativa y que respete los derechos humanos de las poblaciones de Brasil y demás países de la región sin excepción alguna.

Itzhak Levav

Ex-Coordinador del Programa de Salud Mental OPS-OMS

\section{Valentim Gentil responde}

O problema não é o anonimato da Declaração de Caracas, embora poucos saibam quem a elaborou. O problema é o uso que se faz dela.

Levav minimiza a participação de uma entidade privada na sua organização e financiamento, afirmando que Caracas contou “(...) también con el apoyo de instituciones europeas, entre ellas el Instituto Mario Negri (...)" e que "la financiación estuvo a cargo de OPS gracias a una partida especial de US\$ 40.000,00 (...)”.

O parágrafo do meu Editorial que Levav tenta desautorizar é o seguinte:

"Benedetto Saraceno, hoje diretor da Divisão de Saúde Mental da OMS, em Genebra, descreve a estratégia dessa intervenção na política de saúde mental da América Latina, em artigo de 1994. Após patrocinar a conferência de Caracas (cuja "declaração" não é e nem jamais poderia ter sido tomada como se fosse um documento oficial da Organização Pan-Americana da Saúde), seu laboratório em Milão passou a coordenar as iniciativas de um 'consórcio informal' de serviços psiquiátricos europeus para acompanhar países como o Brasil. Segundo Saraceno, o Brasil passou a ser ‘acompanhado' por serviços de Trieste (Rotelli), Ímola (Venturini) e Madrid (Desviat). Os níveis de intervenção desse consórcio são: a) serviços psiquiátricos; b) administrativo; c) docente; d) legislativo; e) político (p.54). Os detalhes desse envolvimento ainda não estão claros."
Levav falta com a verdade. Quem o desmente é o seu diretor e o seu "livro":

"Il progetto [dell' Istituto Mario Negri] è stato realizzato in gran parte con la collaborazione dell'Ufficio Regionale della Organizzazione Mondiale della Sanità (Organización Panamericana de la Salud) e il principale prodotto di tale collaborazione è consistito nella organizzazione della conferenza di Caracas_sugli ospedali psichiatrici nel continente latino americano e nella costituzione di un Consorzio Europeo di assistenza tecnica all'America Latina nel campo della salute mentale". [Saraceno, B. (1994) "Il progetto dell'Istituto Mario Negri: salute mentale in America Latina", Epidemiologia e Psichiatria Sociale 3:49-58].

Segundo os anais de Caracas, as outras "instituições européias" ("Consorzio") eram 4 serviços distritais italianos, 1 espanhol e 1 sueco ligado, como Saraceno, aos sandinistas.

A tradução brasileira confirma, na página $\mathrm{V}$, que a Conferência contou "com o apoio técnico e financeiro do Instituto Mario Negri (...)".

O livro, co-editado por Levav, com a ressalva de que "não é uma publicação formal da Organização Pan-Americana da Saúde", foi publicado em nome da OPAS e do Instituto Mario Negri.

Seu conteúdo, muito longe de identificar tendências mundiais ou sequer latino-americanas, inclui afirmações como: “... a psiquiatria separou um objeto fictício, a 'enfermidade', da existência global do paciente e do grupo social do qual faz parte..." (pág. 23). Por isso não mereceu maior atenção.

Contrariando Levav, meu trabalho resulta de cuidadosa pesquisa. Além do artigo citado no editorial [Gentil, V. (1999) "Uma Leitura Anotada do Projeto Brasileiro de 'Reforma Psiquiátrica", Revista USP, 43:6-23], lança-se um livro documentando do trajeto dessa "reforma".

O material da OMS para o Dia Mundial da Saúde Mental menciona Caracas como uma reunião de "representantes de 11 países da América do Sul" e a experiência de Santos como modelo de "boa prática" na América Latina. Santos aguarda avaliação, mas a representatividade dos poucos convidados sul-americanos que "aclamaram" a Declaração de Caracas foi limitada (um político e um licenciado argentino; cinco defensores do projeto Delgado, além do próprio deputado etc).

Nada disso seria relevante se o objetivo não fosse "desconstruir" a psiquiatria. A exigência basagliana de proibir novos hospitais e modernos asilos não-hospitalares, em vez de proibir os hospitais asilares manicomiais, é essencial para esse "progetto", mas tal fato não funciona nem na Itália.

Apesar disso, nem a "Declaração de Caracas" mandou proibir hospitais. Levav fala em "lodo", mas a palavra certa é dolo.

Valentim Gentil Conselho Diretor do Instituto de Psiquiatria do Hospital das Clínicas da FM/USP 